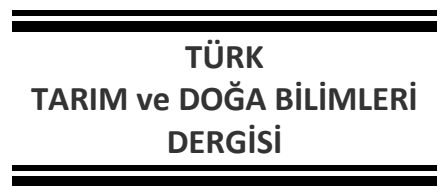

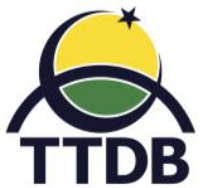

www.dergipark.gov.tr/turkjans

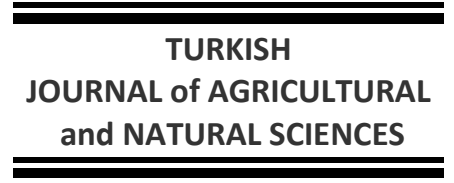

Araştırma Makalesi

\title{
Mardin ili Artuklu ve Kızıltepe İlçelerinde Yetiştirilen Yerel Nar (Punica granatum L.) Genotiplerinin Pomolojik Özelliklerinin Belirlenmesi ${ }^{\mathrm{a}}$
}

\author{
İlyas ÖZTÜRK ${ }^{1}$, Mine PAKYÜREK $^{1 *}$, Ferit ÇELIK ${ }^{2}$ \\ ${ }^{1}$ Siirt Üniversitesi Ziraat Fakültesi Bahçe Bitkileri Bölümü, 56100 Siirt \\ ${ }^{2}$ Yüzüncü Yıl Üniversitesi Ziraat Fakültesi Bahçe Bitkileri Bölümü, 65080 Van \\ *Sorumlu yazar: mine.pakyurek@siirt.edu.tr
}

Geliş Tarihi: 12.07.2019

Düzeltme Geliş Tarihi: 10.10.2019

Kabul Tarihi: 11.10.2019

\section{Özet}

Bu araştırmada, Mardin ili Artuklu ve Kızıltepe ilçelerinde doğal olarak yetişen, yöre iklimine adapte olmuş, üstün kalite özellikli yerel nar genotiplerine ait pomolojik özelliklerin belirlenmesi amaçlanmıştır. Araştırmada 18 genotip üzerinde çalışılmıştır. Çalışma sonucunda; meyve ağırlığının, 207,3-689,5 g; meyve boyunun, 65-95,8 mm; meyve eninin, 72,8-108 mm; kaliks uzunluğunun, 12,1-17,9 mm; kaliks yarıçapının, 9,15-22,5 mm; toplam dane ağırlığının, 84-400 g; 100 dane ağırlığının, 25,3-49,4 g; dane randımanının, \%40,5-78,4; meyve suyu hacminin ise 78-296 ml arasında olduğu tespit edilmiştir. Ayrıca SÇKM, \%15-18; titre edilebilir asit miktarı \%0,060,69 ve $\mathrm{pH}^{\prime}$ nın \%2,38-3,49 arasında olduğu belirlenmiştir. Bunların yanında genotiplerin kabuk alt zemin rengi, kabuk üst zemin rengi, çekirdek sertliği, meyve tadı, dane rengi, odacık sayıları, odacıkların görünümü, daneleme kolaylığı ve meyve posa ağırlıkları tespit edilmiştir. Tartılı derecelendirme yöntemine göre altı genotipin üstün özellik gösterdiği ve ümitvar olduğu kanaatine varılmıştır.

Anahtar kelimeler: Artuklu, Kızıltepe, Mardin, nar, seleksiyon, pomolojik özellikler.

\section{Determination of Pomological Characteristics of Local Pomegranate (Punica granatum L.) Genotypes Grown in Artuklu and Kızıltepe Vicinities, Mardin Province}

\begin{abstract}
In this research, it was aimed to determine pomological properties of local pomegranate genotypes which are naturally grown in Artuklu and Kızltepe districts of Mardin province and adapted to the local climate and have high quality characteristics. In the study, 18 genotypes were studied. At the end of the study, fruit weight ranged from $207,3 \mathrm{~g}$ to $689,5 \mathrm{~g}$, fruit lenght ranged from $65 \mathrm{~mm}$ to $95,8 \mathrm{~mm}$, fruit width ranged from $72,8 \mathrm{~mm}$ to $108 \mathrm{~mm}$, calyx heights ranged from $12,1 \mathrm{~mm}$ to $17,9 \mathrm{~mm}$, calyx half-diameter ranged from $9,15 \mathrm{~mm}$ to 22,5 $\mathrm{mm}$, total seed weight ranged between $84-400 \mathrm{~g}, 100$ seed weight ranged between 25,3-49,4 g, grain yields ranged from $40,5 \%$ to $78,4 \%$, fruit juice volume ranged between $78-296 \mathrm{ml}$ were identified. In addition, total soluble solids (TSS) contents ranged from $15 \%$ to $18 \%$, amount of titrable acidity ranged from $0,06 \%$ to $0,69 \%$ and $\mathrm{pH}$ ranged from 2,38\% to 3,49\% were determined. Moreover these genotypes were observed with regard to the bottom fruit peel color, upper fruit peel color, seed hardness, fruit taste, aril color, chamber number, chamber appearance, easiness of aril separating and fruit pulp weight properties. According to the weighted grading method, six genotypes showed superiority and found to be promising.
\end{abstract}

Key words: Artuklu, Kızıltepe, Mardin, pomegranate, selection, pomological properties.

Giriş

Nar, tarihçesi günümüzden yedi bin yıl öncesine kadar uzanan bir meyvedir. Eski çağda insanların nar meyvesini hem gıda olarak tükettiği, hem de tıbbi amaçlar için kullandığı bilinmektedir. Illk defa nar yetiştiriciliğine bugünkü Pakistan ve Afganistan topraklarında başlanmış, daha sonra İran ve Mezopotamya'ya yayılmıştır (Kaygısız, 2009). 
Narın anavatanı; Güney Kafkasya, İran, Afganistan, Güney Asya, Batı Asya, Anadolu ve Akdeniz arasındaki bölgelerdir. Ayrıca Avrupa ve Afrika'nın Akdeniz sahil bölgelerinde, Çin, Hindistan, Afganistan, İran, Arabistan, Şili, Arjantin, Kaliforniya, Arizona ve Kuzey Meksika'da da nar yetiştiriciliği yapılmaktadır (Özbek, 1977; Dokuzoğuz ve Mendilcioğlu, 1978; Onur, 1983; Kurt ve Şahin, 2013). Dünyada en çok nar üretimi yapan ülkeler arasında Hindistan, İran, Çin, ABD, Türkiye, İspanya, Tunus ve İsrail bulunmaktadır. Öte yandan en büyük nar ihracatçısı ülke İran olup; bu ülkeyi Hindistan, Çin ve ABD takip etmektedir (Yılmaz, 2007). Türkiye ise 2017 yılı itibariyle toplam 502.000 ton nar üretimine sahiptir. Ayrıca mevcut nar bahçelerinde 13.662.000 adet ağaç verim döneminde olup, 3.123.000 adet ağaç da henüz verime yatmamıştır. Akdeniz, Ege ve Güneydoğu Anadolu Bölgelerimiz üretimde ilk üç sırayı almaktadır. Bu bölgelerde, toplam üretimin sırasıyla $\% 53, \% 33$ ve $\% 11^{\prime}$ lik payları gerçekleştirilmektedir (Anonim, 2019).

Pek çok hastalığın tedavisinde kullanılan nar, içeriğindeki flavanoidler nedeniyle güçlü bir antioksidan olduğu tespit edilmiştir. Meyve suyunun ve çekirdek yağının kalp hastalıklarını ve kanseri önlediği belirlenmiştir (Lansky ve ark., 1998). Nar günümüzde de kanser önleyici, antiproliferatif, apoprotik, HIV-I inhibitör, mikrobisit, kardioprotektif, antihiperlipidemik gibi yararlı etkileriyle ön plana çıkmaktadır (Afaq ve ark., 2005). Narın suyu, kabuğu, kurusu ve çekirdeklerinde birçok fenolik bileşeni barındırdı̆̆ı, bu bileşenler arasında Punikalaginin ise en yüksek antioksidan aktiviteye sahip olduğu ifade edilmiştir (Fischer ve ark., 2011).

Nar meyvesi, yenilen kısmında \%80 özsu ve \%20'ye yakın çekirdek içermekte bu özsu içerisinde şeker, organik asitler, vitaminler, polisakkaritler ve gerekli mineralleri bolca barındırmaktadır (AlMaiman ve Ahmad, 2002). Meyveleri tatlı, mayhoş ve ekşi olarak üç şekilde gruplandırılan nar meyvesi daha çok taze ve meyve suyu olarak tüketilirken; tanen, pektin, sirke, sitrik asit, boya ve mürekkep hammaddeleri, yağ, hayvan yemi ve ilaç yapımında da kullanılmaktadır (ikinci, 2007).

Güneydoğu Anadolu bölgesinde karasal iklim hakim olmakla birlikte bölgede bulunan mikroklima alanlarda kapama nar bahçelerine sıkça rastlanmaktadır. Bölgenin tarihi ve kültürel yapısıyla öne çıkan illerinden biri olan Mardin nar yetiştiriciliği açısından da önemli bir potansiyele sahiptir. Bu sebeple yapılan çalışmamızda, Mardin iline bağlı Artuklu ve Kızıltepe ilçelerinde yetiştirilen yerel nar genotiplerinin pomolojik özelliklerinin belirlenmesi ve bu genotipler içinde ümitvar olanların seçilmesi amaçlanmıştır. Çalışma, ümitvar genotiplerin standart çeşit haline getirilmesi ve ticari anlamda üretiminin yaygınlaştırılması sürecinde araştırıcı ve üreticilere sunulan rehber niteliğinde bir çalışma olduğu için önemlidir.

\section{Materyal ve Yöntem}

Bu çalışma, 2017-2018 yıllarında Mardin ilinin Artuklu ilçesine bağı Kabala, Yardere ve Ahmetli mahalleleri (köyleri) ile Kızıltepe ilçesine bağlı Ayaz, Uluköy ve Erdem mahallelerinde (köylerinde) doğal olarak yetiştirilen 18 farklı nar genotipi üzerinde yapılmıştır. Çalışmada yöre iklimine adapte olmuş bölgede yetiştirilen nar genotipleri incelenmiş olup, düzenli ve yüksek verim, güçlü vejetatif gelişme, yeterli miktarda çiçeklenme, yüksek miktarda meyve tutumu, çiçeklenme süresinin kısa olması, iri meyveli, ince kabuklu, aromalı, bol sulu, yumuşak çekirdekli, danelerinin iri ve kırmızı olması, hastalıklara karşı dayanıklı olması ve meyve çatlamasının olmaması veya az olması gibi kriterler dikkate alınarak genotip seçimi yapılmıştır. Uygun genotipleri seçmek amacıyla Mardin iline bağlı Artuklu ve Kızıltepe Tarım İlçe Müdürlüklerinden bilgi alınarak yetiştiriciliğin yaygın olarak yapıldığı köylere gidilip uygun genotipler belirlenmiştir. $\mathrm{Bu}$ şekilde belirlenen her bir genotipe numara verilerek yağlı boya ile işaretlenmiştir. Eylül-Kasım ayları arasında meyveler yeterli SÇKM/asitlik oranına ulaştığı zaman hasat zamanı olarak belirlenmiştir. Meyve hasat döneminde bölgeye gidilerek belirlenen her genotip için ilgili ağaçtan beş meyve örneği alınıp, Siirt Üniversitesi Ziraat Fakültesi Bahçe Bitkileri Bölümü laboratuvarına getirilmiş ve pomolojik analizler yapılmıştır. Meyvelerin fiziksel özellikleri tartılı derecelendirme yöntemine göre değerlendirilmiştir. Meyve ağırlığı, meyve eni ve boyu, meyve hacmi, meyve suyu hacmi, posa ağırlığı, meyvenin kaliks boyu, kaliks yarıçapı, dane randımanı, üst odacık sayısı, alt odacık sayısı, kabuk üst zemin rengi, kabuk alt zemin rengi, meyvenin kabuk kalınlığı, odacıkların dış görünümü, 100 dane ağırlığı, toplam dane ağırlığı, dane randımanı, dane rengi, daneleme kolaylığı, çekirdek sertliği, meyve tadı, meyve suyu randımanı, suda çözünür kuru madde (SÇKM) oranı, titre edilebilir asit miktarı ve meyve suyunun pH'sı ölçülmüştür (Onur, 1983; Yılmaz ve ark., 1995; Tibet ve Onur 1999; Pırlak ve ark., 2003). Seleksiyon kriterleri açısından genotiplerin değerlendirilmesi değiştirilmiş tartılı derecelendirme yöntemine göre yapılmıştır. Bu yönteme göre; meyve ağırlığına \%10, meyve tadına $\% 10$, dane randımanına \%10, meyve suyu randımanına \%20, daneleme kolaylığına \%10, SÇKM'ye \%10, titre edilebilir aside $\% 10$ ve çekirdek sertliğine ise \%20 oranında değer verilerek oluşturulan puan sıralamasıyla öne çıkan ümitvar genotipler tespit edilmiştir (Tablo 1). 


\section{Bulgular ve Tartışma}

Çalışmamızda, belirlenen 18 farklı nar genotipinden alınan beş adet meyve örneğinin fiziksel özellikleri değerlendirilmiş ve bu değerlerin ortalaması verilmiştir. Buna göre ortalama meyve ağılıklarının 207,3-689,5 g arasında değiştiği tespit edilmiştir. Tablo 2'de görüldüğü gibi seçilen nar genotiplerinde $47 \mathrm{~N} 01$ nolu genotip 689,5 g ile en iri meyveye sahip olurken, bunu $673,9 \mathrm{~g}$ değeri ile $47 \mathrm{~N} 14$ nolu genotip izlemiştir. $47 \mathrm{~N} 02$ nolu genotip ise $207,3 \mathrm{~g}$ ile en küçük meyveye sahip olan nar genotipi olmuştur. Meyve ağırlığı 200-300 g arasında olan altı genotip, 300-450 g arasında beş genotip, $450-700 \mathrm{~g}$ arasında ise yedi genotip bulunmuştur. Çalışmamızda incelenen genotipler diğer yörelerdeki genotiplerle karşılaştırıldığında genotiplerimizin yetiştiricilik açısından en önemli kriter olan meyve iriliği bakımından öne çıktığı görülmüştür. Siirt ili Şirvan ilçesinde yapılan bir araştırmada ise, 24 nar genotipinin ortalama meyve ağırlıklarının 161,45-302,35 g arasında olduğu ortaya konulmuştur (Gündoğdu ve ark., 2010). İran'da yetiştirilen 20 nar çeşidinde de meyve ağırlığının 196,89-315 g arasında olduğu belirlenmiştir (Tehranifar ve ark., 2010). İtalya'nın güneydoğusundaki Apulia bölgesinde yetiştirilen sekiz nar genotipinde meyve ağırlıklarının 168,9$574,9 \mathrm{~g}$ arasında olduğu bulunmuştur (Ferrara ve ark., 2011). Şanlıurfa'nın Siverek ilçesinde yapılan farklı bir çalışmada ise, 15 nar tipinde meyve ağırlıklarının ortalama 267,72-650,56 g arasında olduğu belirlenmiştir (Kılıç, 2014). Diyarbakır ili Çermik ve Dicle ilçelerinde yapılan çalışmada ise 10 farklı nar genotipinde meyve ağılıklarının 198,8$366,0 \mathrm{~g}$ arasında değiştiği bildirilmiştir (Cicek ve ark., 2019).

Tablo 1. Değiştirilmiş tartılı derecelendirme yöntemine göre genotiplerin değerlendirilmesi

\begin{tabular}{|c|c|c|c|c|c|c|c|c|c|}
\hline Tipler & $\begin{array}{l}\text { Meyve } \\
\text { ağırlığı } \\
\text { (g) \%10 }\end{array}$ & $\begin{array}{c}\text { Meyve } \\
\text { tadı } \\
\left(\mathrm{cm}^{3}\right) \\
\% 10\end{array}$ & $\begin{array}{c}\text { Dane } \\
\text { randımanı } \\
\% 10\end{array}$ & $\begin{array}{c}\text { Meyve } \\
\text { suyu } \\
\text { randımanı } \\
\% 20\end{array}$ & $\begin{array}{c}\text { Daneleme } \\
\text { kolaylığı } \\
\% 10\end{array}$ & $\begin{array}{c}\text { SÇKM } \\
\% 10\end{array}$ & $\begin{array}{c}\text { Titre } \\
\text { edilebilir } \\
\text { asit } \% 10\end{array}$ & $\begin{array}{c}\text { Çekirdek } \\
\text { sertliği } \\
\% 20\end{array}$ & $\begin{array}{c}\text { Aldığı puan } \\
(\%)\end{array}$ \\
\hline 47 N 01 & 10 & 5 & 7 & 10 & 10 & 5 & 10 & 5 & 62 \\
\hline 47 N 02 & 5 & 10 & 5 & 10 & 10 & 5 & 10 & 15 & 70 \\
\hline 47 N 03 & 5 & 10 & 5 & 10 & 5 & 5 & 10 & 10 & 60 \\
\hline 47 N 05 & 10 & 10 & 5 & 10 & 10 & 10 & 10 & 10 & 75 \\
\hline 47 N 06 & 7 & 5 & 7 & 10 & 10 & 5 & 10 & 5 & 59 \\
\hline 47 N 07 & 5 & 7 & 10 & 20 & 10 & 5 & 5 & 20 & 82 \\
\hline 47 N 08 & 5 & 7 & 5 & 10 & 10 & 10 & 10 & 10 & 67 \\
\hline 47 N 09 & 5 & 5 & 7 & 10 & 10 & 10 & 10 & 10 & 67 \\
\hline 47 N 10 & 10 & 10 & 7 & 10 & 10 & 10 & 10 & 10 & 77 \\
\hline 47 N 12 & 7 & 5 & 7 & 15 & 7 & 5 & 10 & 5 & 61 \\
\hline 47 N 13 & 5 & 10 & 7 & 10 & 10 & 5 & 10 & 5 & 62 \\
\hline 47 N 14 & 10 & 10 & 7 & 15 & 10 & 10 & 10 & 15 & 87 \\
\hline 47 N 15 & 10 & 5 & 7 & 10 & 10 & 10 & 5 & 5 & 62 \\
\hline 47 N 17 & 10 & 10 & 7 & 10 & 10 & 10 & 10 & 15 & 82 \\
\hline 47 N 18 & 10 & 5 & 5 & 10 & 10 & 10 & 5 & 5 & 60 \\
\hline
\end{tabular}

Seçilen nar genotiplerinin meyve boyunun 65 $\mathrm{mm}$ ile $95,8 \mathrm{~mm}$ arasında değiştiği ve en uzun meyveye sahip olan genotipin $95,8 \mathrm{~mm}$ ile $47 \mathrm{~N} 14$ nolu genotip olduğu belirlenmiş; bunu, 93,2 mm değeri ile genotip $47 \mathrm{~N} 18$ takip etmiştir. En küçük meyve boyuna ise 65 $\mathrm{mm}$ ile $47 \mathrm{~N} 02$ nolu genotip sahip olmuştur. Ayrıca meyve boyu 60,0-75,0 mm değerleri arasında olan beş genotip, 75-90 mm değerleri arasında dokuz genotip, 90-100 mm değerleri arasında ise dört genotip tespit edilmiştir. Belirlediğimiz genotiplerde; en düşük meyve eni 72,8 mm olarak 47 N 02' de, en yüksek değer ise $108 \mathrm{~mm}$ ile $47 \mathrm{~N} 01$ nolu genotipte bulunmuştur. Meyve enine göre 70-85 mm değerleri arasında dokuz genotip, 85-95 mm değerleri arasında beş genotip, 95$110 \mathrm{~mm}$ değerleri arasında ise dört genotip tespit edilmiştir. Çalışmamızda elde edilen değerler yapılan diğer çalışmalarla kısmen benzerlik göstermektedir. Örneğin; Şanlıurfa'nın Siverek ilçesinde yapılmış olan bir çalışmada meyve boylarının 69,60 mm ile 92,71 $\mathrm{mm}$ arasında değiştiği bulunmuştur (Kılıç, 2014). Yine Diyarbakır'da yapılmış başka bir çalışmada da meyve boyları için en düşük değer $58,7 \mathrm{~mm}$, en yüksek ise 79,7 mm; meyve eni değeri ise 68,1-86,9 mm değerleri arasında olmuştur (Cicek ve ark., 2019). Irak nar çeşidi Salakhani ile Zivzik narının morfolojik ve pomolojik özelliklerinin karşılaştırıldığı bir başka çalışmada da meyve ağırlığı değerlerinin Salakhani çeşidinde 389,43$578,51 \mathrm{~g}$ arasında, Zivzik çeşidinde ise 129,8-379,5 g arasında değiştiği tespit edilmiştir (Al-Jabbari ve ark., 2019). Genotiplerimizin ortalama en düşük meyve hacmi değeri $200 \mathrm{~cm} 3$ (47 N 02 nolu genotip) olurken, en yüksek değer ise $680 \mathrm{~cm} 3$ (47 N 14 nolu genotip) olmuştur. Meyve hacmi açısından $200-350 \mathrm{~cm}^{3}$ değerleri arasında 10 genotip bulunurken, 350-700 cm3 değerleri arasında ise sekiz genotip yer almıştır. 
Tablo 2. Çalışmada selekte edilen 18 nar genotipinin pomolojik özellikleri

\begin{tabular}{|c|c|c|c|c|c|c|c|c|c|c|c|c|c|}
\hline Tipler & $\begin{array}{l}\text { Meyve } \\
\text { ağırlığı } \\
\text { (g) }\end{array}$ & $\begin{array}{c}\text { Meyve } \\
\text { boyu } \\
\text { (mm) }\end{array}$ & $\begin{array}{c}\text { Meyve } \\
\text { eni } \\
(\mathrm{mm})\end{array}$ & $\begin{array}{c}\text { Meyve } \\
\text { hacmi } \\
\left(\mathrm{cm}^{3}\right)\end{array}$ & $\begin{array}{c}\text { Meyve } \\
\text { yoğunluğu } \\
\left(\mathrm{g} / \mathrm{cm}^{3}\right)\end{array}$ & $\begin{array}{c}\text { Kaliks } \\
\text { uzunluğu } \\
\text { (mm) }\end{array}$ & $\begin{array}{l}\text { Kaliks } \\
\text { yarıçapı } \\
\text { (mm) }\end{array}$ & $\begin{array}{c}\text { Kabuk alt } \\
\text { zemin } \\
\text { rengi }\end{array}$ & $\begin{array}{l}\text { Kabuk üst } \\
\text { zemin rengi }\end{array}$ & $\begin{array}{l}\text { Odacık } \\
\text { görünümü }\end{array}$ & $\begin{array}{c}\text { Alt } \\
\text { odacık } \\
\text { sayısı }\end{array}$ & $\begin{array}{c}\text { Üst } \\
\text { odacık } \\
\text { sayısı }\end{array}$ & $\begin{array}{c}\text { Daneleme } \\
\text { kolaylığı }\end{array}$ \\
\hline 47 N 01 & 689.5 & 91.9 & 108 & 620 & 1.11 & 13.9 & 9.15 & Sarı & Açık Pembe & Belirgin & 4 & 6 & Kolay \\
\hline 47 N 02 & 207.3 & 65.0 & 72.8 & 200 & 1.04 & 14.8 & 13.3 & Sarı & Kırmızı & Belirgin & 3 & 6 & Kolay \\
\hline 47 N 03 & 287.6 & 75.1 & 79.0 & 300 & 0.96 & 15.3 & 16.5 & Sarı & Mor & Belirgin & 3 & 6 & Zor \\
\hline 47 N 04 & 309.5 & 80.5 & 82.9 & 370 & 0.84 & 17.1 & 18.2 & Sarı-yeşil & Kırmızı & Belirgin & 3 & 7 & Zor \\
\hline 47 N 05 & 623.3 & 89.2 & 94.3 & 500 & 1.25 & 17.0 & 22.5 & Sarı-yeşil & Pembe & Belirgin & 3 & 5 & Kolay \\
\hline 47 N 06 & 410.0 & 80.8 & 91.3 & 330 & 1.24 & 12.7 & 16.8 & Sarı & Pembe & Belirgin & 4 & 6 & Kolay \\
\hline $47 \mathrm{~N} 07$ & 221.6 & 69.4 & 82.1 & 300 & 0.74 & 15.6 & 13.0 & Pembe & Kırmızı & Belirgin & 3 & 5 & Kolay \\
\hline 47 N 08 & 246.2 & 71.7 & 77.1 & 220 & 1.12 & 12.1 & 16.5 & Sarı & Kırmızı & Belirgin & 2 & 5 & Kolay \\
\hline 47 N 09 & 255.9 & 70.7 & 78.3 & 300 & 0.85 & 17.9 & 18.9 & Sarı & Pembe & Belirgin & 3 & 6 & Kolay \\
\hline 47 N 10 & 593.9 & 92.4 & 98.8 & 550 & 1.08 & 15.6 & 18.6 & Sarı & Pembe & Belirgin & 4 & 7 & Kolay \\
\hline 47 N 11 & 318.0 & 77.6 & 83.6 & 310 & 1.03 & 17.3 & 18.1 & Sarı-yeşil & Pembe & Belirgin & 3 & 5 & Zor \\
\hline 47 N 12 & 386.6 & 81.3 & 89.7 & 300 & 1.29 & 14.6 & 17.7 & Sarı-yeşil & Pembe & Belirgin & 4 & 6 & Orta \\
\hline 47 N 13 & 279.8 & 74.0 & 81.6 & 270 & 1.04 & 15.7 & 17.1 & Sarı & Mor & Belirgin & 4 & 6 & Kolay \\
\hline 47 N 14 & 673.9 & 95.8 & 102.2 & 680 & 0.99 & 14.1 & 18.3 & Sarı-yeşil & Pembe & Belirgin & 4 & 8 & Kolay \\
\hline 47 N 15 & 533.1 & 88.8 & 95.4 & 520 & 1.03 & 16.6 & 22.5 & Sarı & Kırmızı & Belirgin & 3 & 5 & Kolay \\
\hline 47 N 16 & 311.1 & 76.8 & 80.1 & 320 & 0.97 & 15.8 & 17.5 & Sarı-yeşil & Pembe & Belirgin & 3 & 6 & Kolay \\
\hline 47 N 17 & 499.3 & 89.1 & 94.1 & 660 & 0.76 & 14.3 & 18.3 & Sarı-yeşil & Pembe & Belirgin & 4 & 7 & Kolay \\
\hline 47 N 18 & 523.1 & 93.2 & 94.4 & 500 & 1.05 & 15.9 & 18.7 & Sarı & Pembe & Belirgin & 4 & 8 & Kolay \\
\hline
\end{tabular}


Meyve yoğunluğu değerlerine bakıldığında en düşük değer $0,74 \mathrm{~g} / \mathrm{cm}^{3}$ ile genotip $47 \mathrm{~N} \mathrm{07}$ nin olurken, en yükseği $1,29 \mathrm{~g} / \mathrm{cm}^{3}$ ile $47 \mathrm{~N} 12$ nolu genotipe ait olmuştur. Meyve yoğunluğu bakımından $0,70-1,0 \mathrm{~g} / \mathrm{cm}^{3}$ değerleri arasında yedi genotip, $1,0-1,3 \mathrm{~g} / \mathrm{cm}^{3}$ değerleri arasında ise 11 genotip olduğu belirlenmiştir. Analizi yapılan meyvelerin kaliks uzunluklarının 12,1 mm ile 17,9 $\mathrm{mm}$ arasında olduğu tespit edilmiştir. Kaliks uzunluğu için en uzun değer 17,9 mm ile $47 \mathrm{~N} 09$ nolu genotipte olurken, $47 \mathrm{~N} 08$ nolu genotipin en kısa değere $(12,1 \mathrm{~mm})$ sahip olduğu belirlenmiştir. Buna ek olarak; yedi genotipin kaliks uzunlukları 12$15 \mathrm{~mm}$ değerleri arasında, 11 genotipin ise 15-18 $\mathrm{mm}$ değerleri arasında değiştiği bulunmuştur. Çalışmamıza paralel olarak Tunus'ta yapılan bir çalışmada ise kaliks uzunluğunun 12,00-21,00 mm arasında değiştiği belirlenmiştir (Mars ve Marrakchi, 1999). Kaliks yarıçaplarına gelindiğinde; $47 \mathrm{~N} 05$ ve $47 \mathrm{~N} 15$ nolu genotiplerin en uzun 22,5 mm, $47 \mathrm{~N} 01$ nolu genotipin ise $9,15 \mathrm{~mm}$ ile en kısa kaliks yarı çapı değerine sahip olduğu saptanmıştır. Ölçülen kaliks yarıçapı değerlerine göre 9-17 mm değeri arasında altı genotip, 17-23 mm değeri arasında da 12 genotip bulunmuştur.

Nar genotiplerinin meyve suyu hacmi $296 \mathrm{ml}$ ile $47 \mathrm{~N} 14$ nolu genotipte en fazla bulunurken, bunu sırasıyla $276 \mathrm{ml}$ ile $47 \mathrm{~N} 01$ nolu ve $240 \mathrm{ml}$ ile $47 \mathrm{~N}$ 05 nolu genotipler izlemiştir. En düşük meyve suyu hacmi ise $78 \mathrm{ml}$ ile $47 \mathrm{~N} 02$ nolu genotipte elde edilmiştir. Meyve suyu miktarı, 75-150 ml değeri arasında değişen 8 genotip, $150-300 \mathrm{ml}$ değeri arasında da 10 genotip olduğu belirlenmiştir. Benzer şekilde Taifi varyetesinde yapılan bir çalışmada ise meyve suyu hacminin $156 \mathrm{ml}$ olduğu belirlenmiştir (Al-Maiman ve Ahmad, 2002). Siirt'in Pervari ilçesinde yapılmış bir başka çalışmada da meyve suyu hacmi 76,0-170,0 ml arasında bulunmuştur (Gündoğdu, 2006). Çalışmamızdaki genotipler önceki çalışmalarda incelenen genotiplerle karşılaştırıldığında genotiplerimizin meyve suyu hacimlerinin meyve iriliğine bağlı olarak daha fazla olduğu tespit edilmiştir. Mardin yöresine ait genotiplerin meyve tadına duyusal olarak bakılmış ve Tablo 2'de gösterildiği gibi altı genotip mayhoş, üç genotip ekşi, iki genotip tatlı-mayhoş ve yedi genotip ise tatlı olarak bulunmuştur. Ekşi genotiplerin nar ekşisi üretimine, diğer genotiplerin ise sofralık tüketime uygun olduğu belirlenmiştir. Meyvelerin dane rengi incelendiğinde dokuz genotipin pembe ve dokuz genotipin de kırmızı olduğu belirlenmiştir. Hakkari'nin Çukurca ilçesinde yapılan bir başka çalışmada ise 20 adet nar genotipi incelenmiştir. Bu çalışmada dane renginin üç genotipte beyaz, 10 genotipte açık pembe, beş genotipte pembe ve iki genotipte ise kırmızı olduğu ortaya konulmuştur (Özatak, 2010). Çalışmamızdaki genotiplerde meyvelerin daneleme kolaylığı Tablo 2'de de verildiği gibi 14 genotipte kolay, bir genotipte orta ve üç genotipte zor olarak belirlenmiştir. Tablo 3'te 100 dane ağırlığı en düşük değer 25,3 g ile 47 N 12 nolu genotipte, en yüksek değer ise 49,4 g ile $47 \mathrm{~N} 01$ nolu genotipte tespit edilmiştir. Ayrıca araştırmamızda bu pomolojik özellik açısından değerleri 25-40 g arasında olan 12 genotip, 40-50 g arasında olan altı genotip olduğu belirlenmiştir. Hatay'ın Kırıkhan ilçesinde yürütülen bir çalışmada nar tiplerinin 100 dane ağırlığının 29,0-50,0 g arasında olduğu belirlenmiştir (Polat ve ark., 1999). Siirt'in Pervari ilçesinde yapılan bir çalışmada 100 dane ağırlığı 26,50-45,90 g olarak bulunmuştur (Gündoğdu, 2006). Bu pomolojik özellik açısından da çalışmamızda elde edilen değerler ile diğer çalışmalarda elde edilen değerler benzerlik göstermektedir. Toplam dane ağırlığında da en düşük değer 84 g ile $47 \mathrm{~N} 02$ nolu genotipe, en yüksek değer ise $400 \mathrm{~g}$ ile $47 \mathrm{~N} 01$ nolu genotipe ait olduğu tespit edilmiştir. Toplam dane ağırlığı, 80$160 \mathrm{~g}$ arasında değişen altı genotip, 160-240 g arasında değişen beş genotip ve son olarak 240-400 $\mathrm{g}$ arasında da yedi genotip bulunmuştur. Dane randımanında da en düşük değerin $\% 40,5$ ile $47 \mathrm{~N}$ 02 nolu genotipte, en yüksek değerin ise $\% 78,4$ ile genotip $47 \mathrm{~N} \mathrm{18}$ 'de olduğu belirlenmiş ve ayrıca \%40-50 değerleri arasında beş genotip, \%50-60 değerleri arasında 11 genotip ve $\% 60-80$ değerleri arasında ise iki genotipin yer aldığı bulunmuştur. Yine çalışmamıza benzer olarak yürütülen farklı bir çalışmada dane randımanının \%54-73 arasında olduğu bulunmuştur (Polat ve ark., 1999). Araştırmamızda meyve kabuk kalınlıklarının dört genotipte 2,1-2,7 $\mathrm{mm}$ arasında, 14 genotipte ise 3,1-4,7 mm değerleri arasında değiştiği belirlenmiştir. Hizan'da yapılan çalışmada ise kabuk kalınlığının 1,3-2,8 $\mathrm{mm}$ arasında değiştiği bulunmuştur (Yıldız ve ark., 2003). Tablo 2'de gösterildiği üzere kabuk üst zemin rengi ise iki genotipte mor, 11 genotipte pembe, beş genotipte ise kırmızı olarak tespit edilmiştir. Kabuk alt zemin rengi incelendiğinde de 10 genotipte sarı, yedi genotipte sarı-yeşil ve bir genotipte pembe olduğu belirlenmiştir. Tablo 3'te verilen ve bir diğer pomolojik özellik olan çekirdek sertliği ise dokuz genotipte sert, beş genotipte orta sert, üç genotipte yumuşak ve bir genotip ise çok yumuşak olarak saptanmıştır. Daha önce yapılan başka bir çalışmada ise meyvelerin çekirdek sertliği 12 tipte sert, 11 tipte orta sert, iki tipte yumuşak olarak bulunmuştur (Gündoğdu, 2006). 
Tablo 3. Çalışmada selekte edilen 18 nar genotipinin pomolojik özellikleri.

\begin{tabular}{|c|c|c|c|c|c|c|c|c|c|c|c|c|c|c|}
\hline Tipler & $\begin{array}{c}\text { Şekil } \\
\text { indeksi }\end{array}$ & $\begin{array}{c}\text { Kabuk } \\
\text { kalınlığı } \\
\text { (mm) }\end{array}$ & $\begin{array}{l}\text { Toplam } \\
\text { dane } \\
\text { ağırlığı } \\
\text { (g) }\end{array}$ & $\begin{array}{l}100 \\
\text { dane } \\
\text { ağırlığı } \\
\text { (g) }\end{array}$ & $\begin{array}{c}\text { Dane } \\
\text { randımanı } \\
(\%)\end{array}$ & $\begin{array}{l}\text { Dane } \\
\text { rengi }\end{array}$ & $\begin{array}{c}\text { Çekirdek } \\
\text { sertliği }\end{array}$ & $\begin{array}{c}\text { Meyve } \\
\text { posası } \\
\text { (kabuk+posa) } \\
\text { (g) }\end{array}$ & Meyve tadı & $\begin{array}{l}\text { Meyve } \\
\text { suyu } \\
\text { hacmi } \\
\text { (ml) }\end{array}$ & $\begin{array}{c}\text { Meyve } \\
\text { suyu } \\
\text { randımanı } \\
(\%)\end{array}$ & $\begin{array}{c}\text { SÇKM } \\
\text { (\%) }\end{array}$ & $\begin{array}{c}\text { Titre } \\
\text { edilebilir } \\
\text { asit (\%) }\end{array}$ & $\begin{array}{l}\mathrm{pH} \\
\text { (\%) }\end{array}$ \\
\hline $47 \mathrm{~N} 01$ & 0.85 & 4.60 & 400.0 & 49.4 & 58.0 & Pembe & Sert & 372.2 & Mayhoş & 276 & 40 & 15.2 & 0.33 & 2.96 \\
\hline 47 N 02 & 0.89 & 2.10 & 84.0 & 25.8 & 40.5 & Pembe & Yumuşak & 129.2 & Tatlı & 78 & 38 & 15.0 & 0.10 & 3.27 \\
\hline $47 \mathrm{~N} 03$ & 0.95 & 3.12 & 141.5 & 38.6 & 49.2 & Kırmızı & Orta Sert & 179.8 & Tatlı & 100 & 35 & 16.4 & 0.11 & 3.48 \\
\hline 47 N 04 & 0.97 & 4.50 & 151.2 & 29.8 & 49.0 & Kırmızı & Sert & 194.0 & Ekşi & 100 & 32 & 17.0 & 0.51 & 2.62 \\
\hline $47 \mathrm{~N} 05$ & 0.95 & 3.92 & 308.4 & 47.4 & 49.0 & Pembe & Orta Sert & 316.0 & Tatlı & 240 & 39 & 18.0 & 0.08 & 2.96 \\
\hline 47 N 06 & 0.88 & 3.30 & 214.3 & 40.8 & 52.3 & Pembe & Sert & 173.5 & Mayhoş & 160 & 39 & 16.0 & 0.33 & 2.67 \\
\hline 47 N 07 & 0.85 & 2.43 & 165.3 & 49.2 & 74.6 & Pembe & $\begin{array}{c}\text { Çok } \\
\text { Yumuşak }\end{array}$ & 121.0 & $\begin{array}{c}\text { Tatlı- } \\
\text { mayhoş }\end{array}$ & 120 & 54 & 15.0 & 0.69 & 3.15 \\
\hline 47 N 08 & 0.93 & 4.30 & 114.7 & 36.3 & 47.0 & Kırmızı & Orta Sert & 132.1 & $\begin{array}{c}\text { Tatlı- } \\
\text { mayhoş }\end{array}$ & 84 & 34 & 17.6 & 0.30 & 2.65 \\
\hline 47 N 09 & 0.90 & 3.60 & 140.0 & 36.4 & 55.0 & Pembe & Orta Sert & 147.7 & Mayhoş & 90 & 35 & 18.0 & 0.29 & 2.90 \\
\hline 47 N 10 & 0.94 & 3.10 & 350.0 & 45.8 & 59.0 & Pembe & Sert & 276.4 & Tatlı & 235 & 40 & 17.4 & 0.09 & 3.01 \\
\hline 47 N 11 & 0.93 & 2.60 & 174.2 & 29.6 & 54.8 & Kırmızı & Orta Sert & 184.7 & Ekşi & 120 & 38 & 17.4 & 0.47 & 2.75 \\
\hline 47 N 12 & 0.91 & 3.07 & 228.8 & 25.3 & 59.2 & Kırmızı & Sert & 208.0 & Mayhoş & 160 & 41 & 16.4 & 0.39 & 2.38 \\
\hline 47 N 13 & 0.91 & 3.10 & 151.0 & 40.3 & 53.4 & Pembe & Sert & 167.5 & Tatlı & 106 & 38 & 16.0 & 0.08 & 2.96 \\
\hline 47 N 14 & 0.94 & 3.80 & 366.0 & 37.0 & 54.3 & Kırmızı & Yumuşak & 338.2 & Tatlı & 296 & 44 & 17.4 & 0.09 & 2.96 \\
\hline 47 N 15 & 0.93 & 2.70 & 309.4 & 38.8 & 58.0 & Pembe & Sert & 244.6 & Mayhoş & 206 & 39 & 16.6 & 0.46 & 2.62 \\
\hline 47 N 16 & 0.96 & 4.60 & 184.9 & 30.5 & 59.4 & Kırmızı & Sert & 183.3 & Ekşi & 206 & 66 & 17.4 & 0.51 & 2.66 \\
\hline 47 N 17 & 0.95 & 4.70 & 252.0 & 32.7 & 50.5 & Kırmızı & Yumuşak & 274.0 & Tatlı & 190 & 38 & 16.6 & 0.06 & 3.49 \\
\hline 47 N 18 & 0.99 & 3.20 & 253.0 & 38.8 & 78.4 & Kırmızı & Sert & 303.0 & Mayhoş & 180 & 34 & 17.0 & 0.43 & 2.57 \\
\hline
\end{tabular}


Genotiplerin alt odacık sayılarına bakıldığında; bir genotipte iki, dokuz genotipte üç ve sekiz genotipte ise dört adet olarak belirlenmiştir. Üst odacık sayıları ise beş genotipte beş, sekiz genotipte altı, üç genotipte yedi ve iki genotipte de sekiz adet olmuştur. Başka bir çalışmaya göre meyvelerin odacık sayısı sekiz tipte 6 , sekiz tipte 7, altı tipte 8 adet olarak saptanmıştır. Aynı çalışmada odacık görünümü ise 25 tipte belirgin olarak saptanmıştır (Gündoğdu, 2006). Buna karşılık bizim çalışmamızda seçilen nar genotiplerinin odacık görünümü, 18 genotipte de belirgin olarak tespit edilmiştir.

Meyvelerin şekil indeksi incelendiğinde, Tablo 3'te görüldüğü gibi en düşük değerin 0,85 ile $47 \mathrm{~N} 01$ ve $47 \mathrm{~N} 07$ nolu genotiplerde, en yüksek değerin ise 0,99 ile $47 \mathrm{~N} 18$ nolu genotipte olduğu belirlenmiştir. Yedi genotip, 0,85-0,92 değerleri arasında; 11 genotip de 0,92-0,99 değerleri arasında bulunmuştur. Meyve suyu randımanının \%32-66 değerleri arasında olduğu tespit edilmiştir. Meyve suyu randımanı için \%32 ile en düşük değer 47 N 04 nolu genotipte bulunurken, en yüksek değer ise \%66 ile $47 \mathrm{~N} 16$ genotipte bulunmuştur. Buna ek olarak; \%30-40 değerleri arasında 14 genotip, \%41-50 değerleri arasında iki genotip ve \%50-70 değerleri arasında iki genotip olduğu tespit edilmiştir. Genotiplere ait meyvelerin suda çözünebilir kuru madde (SÇKM) miktarlarının \%15 ile \%18 arasında değiştiği görülmüştür. En yüksek değerin \%18 değeri ile $47 \mathrm{~N} 05$ ve $47 \mathrm{~N} 09$ nolu genotiplerde olduğu belirlenmiş, bunu \%17,6 ile $47 \mathrm{~N} 08$ nolu genotip izlemiş ve en düşük değer ise \%15 ile $47 \mathrm{~N} 02$ ve 47 $\mathrm{N} 07$ nolu genotiplerde ortaya çıkmıştır. Ayrıca \%1516,5 oranları arasında 7 genotip, $\% 16,5-18$ oranları arasında ise 11 genotip bulunmuştur. Genotiplere ait meyvelerin $\mathrm{pH}$ değerlerinin \%2,38 ile 3,49 arasında değiştiği tespit edilmiştir. $\mathrm{pH}$ değeri \%3,49 ile en yüksek olan değer $47 \mathrm{~N} 17$ nolu genotip için olurken, en düşük $\mathrm{pH}$ değeri ise \%2,38 ile $47 \mathrm{~N} 12$ nolu genotipte gözlenmiştir. Bunun yanında \%2,38 ile 3,0 değerleri arasında 13 genotip, $\% 3,0$ ile 3,49 değerleri arasında ise beş genotip bulunmuştur. Tablo 3'e göre, nar genotiplerinin titre edilebilir asit miktarlarının \%0,06 ile \%0,69 arasında değiştiği tespit edilmiştir. Asitlikte \%0,69 ile $47 \mathrm{~N} 07$ nolu genotip en yüksek değere sahip olurken, en düşük değerin \%0,06 ile $47 \mathrm{~N} 17$ nolu genotipe ait olduğu görülmektedir. Asitlik değerleri $\% 0,06$ ile 0,40 arasında olan 12 genotip, \%0,40 ile 0,70 değerleri arasında ise altı genotip olduğu bulunmuştur. Çalışmamıza benzer olarak yapılmış farklı araştırmalar literatürde göze çarpmaktadır. Örneğin; Siirt (Pervari) yöresinde yapılan çalışmada meyve ağırlıkları 197-310 gr, meyve yüksekliği 61-74 $\mathrm{mm}$, meyve enleri 71-84 mm, meyve hacimleri 100$300 \mathrm{ml}$, meyve suyu hacimleri 52-126 ml, meyve yoğunlukları 0.68-2.05 g/cm3, SÇKM miktarları \%11$23, \mathrm{pH}$ değerinin 3,30-3,93 ve toplam asitliğin \%0,31,1 arasında değiştiği bildirilmiştir (Kazankaya ve ark., 2003). Yine Muradoğlu ve ark. (2006) tarafından 46 nar genotipi üzerinde yapılmış olan bir çalışmada meyve ağırlıklarının 131-337 g, meyve boyunun 60,0- $81 \mathrm{~mm}$, meyve yarıçapının 30,8-88,9 $\mathrm{mm}$, kaliks uzunluğunun 11,0-26,1 mm, kaliks yarıçapının 11,2-18,1 mm arasında değiştiği bulunurken, SÇKM oranının \%12,2-17,6 arasında, $\mathrm{pH}$ değerinin 2,6-3,8 arasında, asitliğin ise \%1,5-2,9 arasında olduğu saptanmıştır. Hizan'da yapılan bir diğer çalışmada ise meyve ağırlığının 192-388 g, meyve boyunun $62-78 \mathrm{~mm}$, meyve çapının 68-90 mm, meyve suyu oranının \%28-55, kabuk kalınlığının 1,3-2,8 mm, SÇKM'nin \%10-17 ve asitlik oranının da \%0,37-4,3 arasında değiştiği bildirilmiştir (Yıldız ve ark., 2003). Tibet ve Onur'un (1999) Akdeniz ve Güneydoğu Anadolu bölgelerine ait 35 nar tipinin fenolojik ve pomolojik özelliklerini inceledikleri çalışmada da meyve ağırlıkları 223-493 g, meyve eni 78-102 mm, meyve uzunluğu 67-88 $\mathrm{mm}$, SÇKM oranı \%12-16, dane verimi \%41-64 ve toplam asitlik oranı \%0,19-2,38 aralığında bulunmuştur.

\section{Sonuç ve Öneriler}

Çalışmanın yapıldığı Mardin ili Artuklu ve Kızıltepe ilçelerinde çok eski yıllardan beri nar yetiştiriciliği yapılmaktadır. Mardin ilinde yetiştiriciliği yapılan nar genotipleri üzerinde şimdiye kadar herhangi bir seleksiyon çalışması yapılmamıştır. İncelediğimiz nar genotiplerinin irilik, meyve suyu hacmi bakımından yüksek değerlere sahip olması, tad ve aromalarının iyi olması, çekirdeklerinin yumuşak olması, büyük oranda daneleme kolaylığına sahip olmaları, sofralık tüketimde, meyve suyu üretiminde ve nar ekşisi üretiminde tercih nedeni olmakta ve bölgedeki narların önemini arttırmaktadır.

Araştırmamızda sofralık tüketime uygun olan mayhoş, tatlı-mayhoş ve tatlı olan 15 nar genotipinde değiştirilmiş tartılı derecelendirme yöntemi kullanılarak genotiplere göre belirlenen sekiz kriter açısından puanlama yapılmıştır. Ekşi olan $47 \mathrm{~N} \mathrm{04,} 47 \mathrm{~N} 11$ ve $47 \mathrm{~N} 16$ nolu üç genotip ise nar ekşisi üretiminde kullanılmaya uygun bulunduğundan bu üç genotip tartılı derecelendirme yönteminde değerlendirmeye alınmamıştır. Sofralık tüketime uygun altı nar genotipinin ise seleksiyon ıslahı açısından kabul edilen temel kriterler göz önüne alındığında standart çeşitlerle ve önceki çalışmalarla öne çıkarılmış ümitvar genotiplerle rekabet edilebileceği görülmektedir. 
Türkiye, hem narın anavatanı hem de yetiştiricilik açısından uygun ekolojik şartlara sahip olması nedeniyle mevcut üretim potansiyelini arttıracak çalışmalar yapmalıdır. Uzun vadede yapılacak çalışmalar ile mevcut çeşit ve genotiplerimizin belirlenip tanımlanması ve bunları standartlaştırarak üretimlerinin arttırılması doğru bir adım olacaktır.

Bölgedeki ümitvar nar genotiplerinin tespit edilmesine ve bölgenin nar üretim potansiyelinin belirlenmesine zemin hazırlayan bu çalışma ile bölgede yetişen narların özelliklerinin tespit edilerek bundan sonra yapılacak olan çalışmalara ışık tutulmasına, seçilen genotiplerin kurulacak yeni kapama bahçeler için yöre çiftçisine tavsiye edilerek üretiminin yaygın hale getirilmesine ve böylece bölge ekonomisinin kalkınmasına katkı sağlanacaktır. Ayrıca bölgede nar yetiştiriciliği konusunda üreticilerin bilgilendirilmesi ve hasat edilen ürünün sağlıklı ve uzun süreli olarak pazarlanabilmesi için kontrollü atmosferli soğuk hava depolarının kurulması ve yaygınlaştırılması gerekmektedir.

Çalışmamızın sonucunda sofralık tüketim için üstün özellik gösterdiği ve ümitvar olduğu kanaatine varılan 47 N 02, 47 N 05, 47 N 07, 47 N 10, 47 N 14, ve $47 \mathrm{~N} 17$ nolu genotiplerin çoğaltılıp, yaygınlaştırılması ve yöre üretimine kazandırılması önerilebilir. Üstün özellik gösterdiği ve ümitvar olduğu kanaatine varılan genotiplerin iri meyveli, bol sulu, tad ve aroma bakımından güzel ve yumuşak çekirdekli olması gibi nitelikleri dikkate alındığında bunların birer çeşit adayı olması yolunda çalışmalara başlanması Güneydoğu Anadolu bölgesi meyveciliğinde verim ve kalitenin arttırılması açısından son derece önemlidir.

${ }^{a}$ Bu makale, İlyas ÖZTÜRK'ün Yüksek Lisans Tez çalışmasından üretilmiştir.

\section{Kaynaklar}

Al-Jabbari, K. H., Pakyürek, M., Yaviç, A. 2019. Identification of morphological and pomological characteristics of Iraq pomegranate (Punica granatum L.) variety Salakhani and comparing with variety Zivzik. International Journal of Secondary Metabolite, 6(3): 270-282.

Anonim, 2019. www.tarimsalistatistik.com/trTR/sayfa/nar-istatistikleri. (Erişim tarihi: 09.07.2019).

Afaq, F., Saleem, M., Krueger, C.G., Reed J.D., Mukhtar, H. 2005. Anthocyanin and hydrolyzable tanin-rich pomegranate fruit extract modulates MAPK and NF-KB pathways and inhibits skin tumorigenesis in
CD-1 Mice. International Journal of Cancer, 113: 423-433.

Al-Maiman, S.A., Ahmad, D. 2002. Changes in physical and chemical properties during pomegranate (Punica granatum L.) fruit maturation. Food Chemistry, 76: 437-441.

Cicek, M., Pakyurek, M., Celik, F. 2019. Determination of morphological and pomological characteristics of pomegranate (Punica granatum L.) genotypes grown in Diyarbakır. Int. J. Agric. Environ. Food Sci., 3(3), 196-202.

Dokuzoğuz, M., Mendilcioğlu, K. 1978. Ege Bölgesi nar çeşitleri üzerinde pomolojik çalışmalar. Ege Üniversitesi Ziraat Fakültesi Dergisi, 15(12): 133-159.

Ferrara, G., Cavoski, I., Pacifico, A., Tedone, L., Mondelli, D. 2011. Morpho-pomological and chemical characterization of pomegranate (Punica granatum L.) genotypes in Apulia Region, Southeastern Italy. Scientia Horticulturae, 130: 599-606.

Fischer, U.A., Carle, R., Kammerer, D.R. 2011. Identification and quantification of phenolic compounds from pomegranate (Punica granatum L.) peel, mesocarp, aril and differently produced juices by HPLC-DADESI/M Sn. Food Chemistry, 127(2): 807-821.

Gündoğdu, M. 2006. Pervari (Siirt) Yöresi Nar (Punica granatum L. ) Populasyonlarında Mahalli Tiplerin Seleksiyonu. Yüksek Lisans Tezi. Yüzüncü Yıl Üniversitesi, Fen Bilimleri Enstitüsü, Van.

Gündoğdu, M., Yılmaz, H., Şensoy, R.I.G., Gündoğdu, Ö., 2010. Şirvan (Siirt) yöresinde yetiştirilen narların pomolojik özellikleri. Yüzüncü Yıl Üniversitesi Tarım Bilimleri Dergisi, 20(2): 138-143.

İkinci, A., 2007. Nar Yetiştiriciliği. Tarım Türk Dergisi, 7: 12-16.

Kaygısız, H. 2009. Narın Tarihçesi ve Önem Kazanmasının Nedenleri. Hasad Dergisi, 24(2): 64-66.

Kazankaya, A., Gündoğdu, M., Aşkın, MA., Muradoğlu, F. 2003. Pervari (Siirt) narlarının meyve özellikleri. IV. Ulusal Bahçe Bitkileri Kongresi, Eylül 08-12, Antalya, s. 141-143.

Kılıç, M.E. 2014. Siverek Yöresi (Şanlıurfa) Narların (Punica granatum L.) Morfolojik ve Pomolojik Karakterizasyonu, Yüksek Lisans Tezi, Harran Üniversitesi Fen Bilimleri Enstitüsü, Şanlıurfa, s. 31-47.

Kurt, H., Şahin, G. 2013. Bir Ziraat Coğrafyası Çalışması: Türkiye'de Nar (Punica granatum L.) Tarımı. Marmara Coğrafya Dergisi, 27: 551-574. 
Lansky, E., Shubert, S., Neeman, I. 1998. Pharmological and therapeutic properties of pomegranate. I. International Symposium of Pomegranate, Orihuela (Alicante) Spain, pp. 231-235.

Mars, M., Marakchi, M. 1999. Diversity of pomegranate (Punica granatum L.) germplasm in Tunisia. Genetic Research Crop Evolation, 46: 461-467.

Muradoğlu, F., Balta, F.M., Özrenk, K. 2006. Pomegranate (Punica granatum L.) genetic resources from Hakkari, Turkey. Research Journal of Agricultural and Biological Sciences, 2: 520-525.

Onur, C. 1983. Akdeniz Bölgesi Narlarının Seleksiyonu. Doktora Tezi. Alata Bahçe Kültürleri Araştırma Eğitim Merkezi. Mersin, No: 46.

Özatak, Ö.F. 2010, Çukurca (Hakkâri) Yöresi Nar (Punica granatum L.) Genotiplerinin Özellikleri, Yüzüncü Yıl Üniversitesi Fen Bilimleri Enstitüsü Bahçe Bitkileri Anabilim Dalı, Yüksek Lisans Tezi, Van. 76 s.

Özbek, S. 1977. Genel Meyvecilik. Çukurova Üniversitesi Ziraat Fakültesi Yayınları, No. 111.

Pırlak, L., Güleryüz, M., Aslantaş, R., Eşitken, A. 2003. Promising native summer apple (Malus domestica) cultivars from NorthEastern Anatolia, Turkey. New Zealand Journal of Crop and Horticultural Science, 31: 311-314.

Polat, A.A., Durgaç, C., Kamiloğlu, Ö., Mansuroğlu, M. 1999. Hatay'ın Kırıkhan ilçesinde yetiştirilmekte olan bazı nar tiplerinin pomolojik özelliklerinin belirlenmesi üzerinde çalışmalar. Türkiye 3. Ulusal Bahçe Bitkileri Kongresi, 14-17 Eylül, Ankara.

Tehranifar, A., Zarei, M., Nemati, Z., Esfendiyari, B., Vazifeshenas, M.R. 2010. Investigation of physicochemical properties and antioxidant activity of twenty Iranian pomegranate (Punica granatum L.) cultivars. Science Horticulture, 126: 180-185.

Tibet, H., Onur, C. 1999. Antalya'da nar (Punica granatum L.) çeşit adaptasyonu. Türkiye 3. Ulusal Bahçe Bitkileri Kongresi, 14-17 Eylül, Ankara, s. 31-35.

Yıldız, K., Muradoğlu, F., Oguz, H. I.., Yılmaz, H. 2003. Pomological features of the pomegranates growing in Hizan. Antalya, Turkey. IV. National Horticulture Congress. 08-12 September, pp. 238-240.

Yılmaz, H., Ayanoğlu, H., Yıldız, A. 1995. Ege Bölgesi'nde selekte edilen bazı nar tiplerinin Erdemli koşullarında adaptasyonu üzerine araştırmalar. Türkiye II. Ulusal Bahçe Bitkileri Kongresi, 3- 6 Ekim, Adana, s. 691-695.

Yılmaz, C. 2007. Nar. Hasad Yayıncılık. İstanbul, 190 s. 